\title{
Evaluation of Aortic Elasticity \\ Parameters in Survivors of COVID-19 \\ Using Echocardiography Imaging
}

\author{
Uğur Küçük Emine Gazi Ali Duygu Ercan Akşit \\ Department of Cardiology, Faculty of Medicine, Canakkale Onsekiz Mart University, Canakkale, Turkey
}

\section{Highlights of the Study}

- Aortic elasticity is a well-established surrogate marker of cardiovascular risk.

- Severe acute respiratory syndrome coronavirus 2-induced endothelial cell injury can lead to arterial wall dysfunction.

- The use of transthoracic echocardiography may be helpful in evaluating aortic elasticity parameters for cardiovascular risk stratification in COVID-19 survivors.

\section{Keywords}

COVID-19 · Arterial stiffness · Echocardiography ·

SARS-CoV-2

\begin{abstract}
Objective: While severe acute respiratory syndrome coronavirus 2 (SARS-CoV-2) primarily affects lung tissue, it may cause direct or indirect damage to the cardiovascular system, and permanent damage may occur. Arterial stiffness is an early indicator of cardiovascular disease risk. The aim of our study was to establish the potential effects of SARSCoV-2 on the vascular system evaluated by transthoracic echocardiographic examination. Subjects and Methods: This study compared arterial stiffness between the survivors of COVID-19 and those without a history of COVID-19 infection. The difference in aortic diameter was examined using echocardiography. Results: The study included 50 patients who survived COVID-19 in the last 3-6 months and 50 ageand gender-matched healthy volunteers. In surviving COVID-19 patients, aortic diastolic diameter in $\mathrm{cm}$ ([3.1 \pm 0.2$]$ vs.
\end{abstract}

$[2.9 \pm 0.1], p<0.001)$, pulse pressure (PP) ([43.02 \pm 14.05$]$ vs. $[35.74 \pm 9.86], p=0.004)$, aortic distensibility ([5.61 \pm 3.57$]$ vs. $[8.31 \pm 3.82], p<0.001)$, aortic strain ([10.56 \pm 4.91$]$ vs. [13.88 $\pm 5.86], p=0.003), \mathrm{PP} /$ stroke volume index ([1.25 \pm 0.47$] \mathrm{vs}$. $[0.98 \pm 0.28], p=0.001)$, and aortic stiffness index ([2.82 \pm 0.47 ] vs. [2.46 \pm 0.45$], p<0.001)$ were statistically significant compared to the control group. Conclusion: SARS-CoV-2 may cause reduced or impaired aortic elasticity parameters linked to impaired arterial wall function in COVID-19 survivors compared with controls. @2022 The Author(s).

Published by S. Karger AG, Basel

\section{Introduction}

COVID-19 emerged in Wuhan, China in 2019 and impacted communities all over the world in a short period of time [1]. Although the disease primarily affects the respiratory system due to the dominance of aerosol transmission, it is also known to cause multisystem involvement, including the cardiovascular system [2]. It was
C 2022 The Author(s).

Published by S. Karger AG, Basel

This is an Open Access article licensed under the Creative Commons Attribution-NonCommercial-4.0 International License (CC BY-NC) (http://www.karger.com/Services/OpenAccessLicense), applicable to the online version of the article only. Usage and distribution for commercial purposes requires written permission.
Correspondence to:

Uğur Küçük, drugurkucuk@hotmail.com 
shown that patients with COVID-19 experience changes in vascular tone especially due to endothelial cell function [3]. A change in vascular tone is a sign of aortic stiffness, manifested mainly by a loss of elasticity of the large blood vessels, which increases with advanced age. It triggers atherosclerosis and causes serious cardiovascular problems, such as hypertension, coronary artery disease, heart failure, and stroke [4].

Elevated cholesterol, blood pressure (BP) values, and body weight are traditional cardiovascular risk factors, and it is possible for some patients to have cardiovascular diseases without risk factors [5]. Therefore, there is a need for clinical use of supplementary criteria in addition to traditional risk factors. Adverse arterial remodeling is inevitable due to loss of arterial elasticity. Impairment of arterial elasticity is an independent predictor for cardiovascular event risk [6]. Aortic elasticity, indicative of vascular stiffness, is expressed as the aortic stiffness index (ASI) and aortic distensibility (AD). A decrease in elasticity is inversely proportional to the ASI and directly proportional to the AD [7]. Assessment of arterial stiffness may include noninvasive applanation tonometry, echocardiography, and magnetic resonance imaging. Carotidfemoral pulse wave velocity (PWV) is especially recommended as the gold standard method for assessing arterial stiffness [8]. Although the PWV technique is widely used, echocardiography has not been adequately used [9]. Echocardiography results are more valuable because central arterial stiffness is more specific in predicting cardiovascular outcomes than peripheral arterial stiffness [10]. Pulse pressure (PP) is often used to estimate global arterial stiffness. However, the use of PP alone may not be sufficient as PP is associated with stroke volume (SV) [11]. Therefore, data obtained as a ratio of PP to SV index (SVi) (PP/SVi) will provide more reasonable estimates of arterial stiffness. In light of the abovementioned information, this study aimed to evaluate whether there is a difference in arterial stiffness between the survivors of COVID-19 and those without a history of COVID-19 infection and the effect of COVID-19 on arterial stiffness.

\section{Subjects and Methods}

\section{Study Population}

Our study was a case-control cross-sectional study conducted in a tertiary health center. The study included 50 patients who were admitted to our cardiology outpatient clinic and survived COVID-19 in the last 3-6 months and 50 age- and gender-matched healthy volunteers. Patients with positive polymerase chain reaction test result were included in the COVID-19 survivors group.

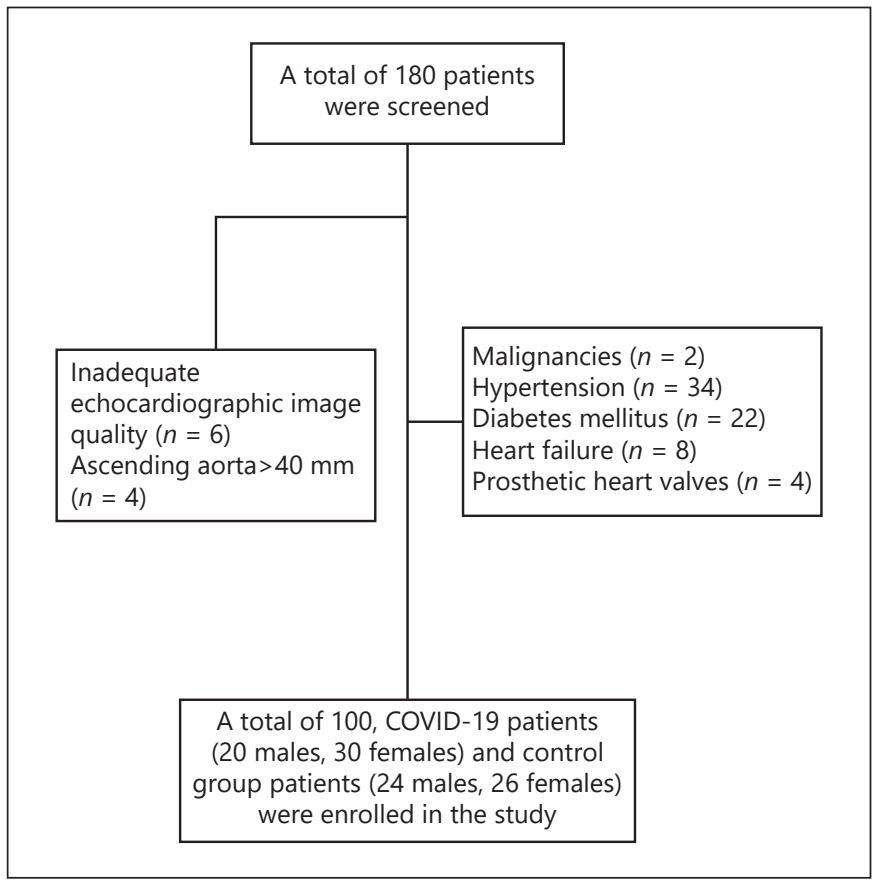

Fig. 1. Flowchart of study selection.

Combined throat/nasal swabs for polymerase chain reaction tests were taken in accordance with the guidelines of the Republic of Turkey Ministry of Health and the World Health Organization. Hospital admission occurred in line with the recommendations of the scientific committee in our country [12]. In the presence of the specified criteria, patients were hospitalized: (1) moderate/severe pneumonia (patients with bilateral widespread pneumonia findings on their chest X-ray or tomography, hypotension $(<90 / 60 \mathrm{~mm}$ $\mathrm{Hg}$ ) according to the preliminary clinical evaluation, tachypneic $(\geq 30 / \mathrm{min})$ or those that had arterial oxygen saturation level below $93 \%$ without supplemental oxygen), or severe laboratory parameters (ferritin value $>1,000 \mathrm{ng} / \mathrm{mL}$ or high-sensitivity C-reactive protein $>40 \mathrm{mg} / \mathrm{dL}$ or lymphope) despite unilateral infiltration in the lung. In the presence of the following specified criteria, the patients were admitted to the intensive care unit: (1) respiratory rate of $\geq 30 / \mathrm{min}$, oxygen saturation of $<90 \%$, and partial oxygen of 70 $\mathrm{mm} \mathrm{Hg}$, considering nasal oxygen supplement of $>5 \mathrm{~L}$ per min, tachycardia (100 beats/min), systolic BP of $90 \mathrm{~mm} \mathrm{Hg}$, mean arterial $\mathrm{BP}$ of $65 \mathrm{~mm} \mathrm{Hg}, \mathrm{PaO}_{2} / \mathrm{FiO}_{2} \leq 300$, and lactate levels $>2$ $\mathrm{mmol} / \mathrm{L}$.

We excluded patients with a history of cerebrovascular disease, severe renal and liver failure, malignant disease, atrial fibrillation and atrial flutter, hypertension and diabetes mellitus, heart failure, moderate or severe heart valve stenosis or insufficiency, history of coronary artery bypass surgery, prosthetic heart valves, connective tissue diseases such as Marfan syndrome, ascending aorta $>40 \mathrm{~mm}$, bicuspid aortic valve, poor echocardiographic window, and patients younger than 18 years of age. The flowchart for the study is shown in Figure 1.

Demographic characteristics of all patients were recorded. Laboratory parameters were taken from the hospital automation sys- 
Fig. 2. Measurement of systolic and diastolic diameters of the ascending aorta with transthoracic M-mode echocardiography.

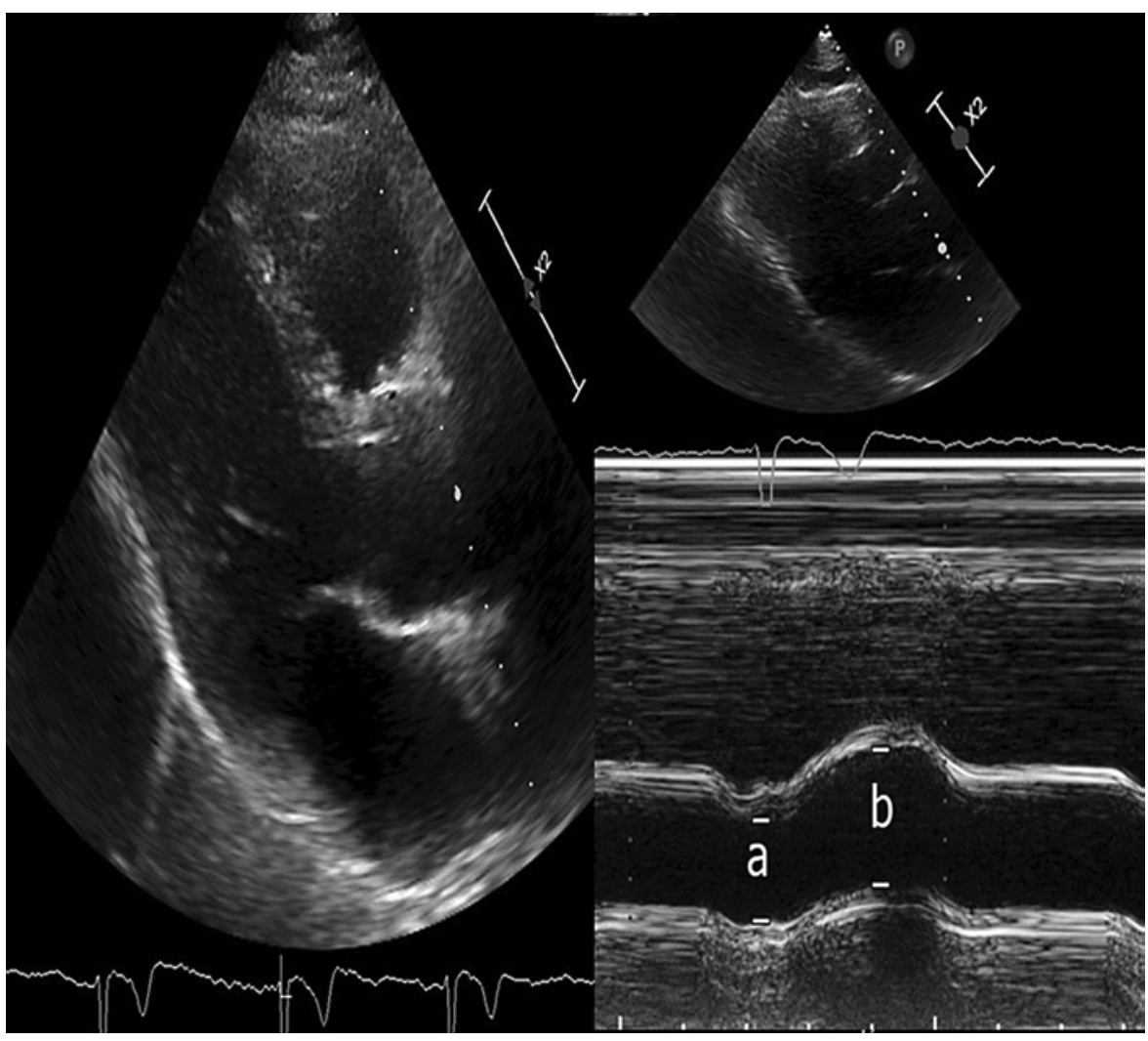

tem and recorded. Left ventricular ejection fraction $\leq 40 \%$ was defined as heart failure with reduced left ventricular function. Fever was determined as body temperature of $\geq 38^{\circ} \mathrm{C}$.

\section{Echocardiographic Imaging Protocol}

Since arterial BP values of the patients were used to calculate the ASI, and BP levels were measured just prior to initiation of echocardiographic imaging. The measurements were performed in the echocardiography laboratory on the right and left arm after 15 min of rest in a seated position in a quiet environment. BP was measured twice with an oscillometric sphygmomanometer at 5 min intervals. The average of the measurements was used for analysis. Systolic BP and diastolic BP were recorded, and the difference between them was defined as the PP. Following the BP measurements, echocardiographic examinations were performed.

Echocardiographic examinations were performed by simultaneous electrocardiography using a Philips EPIQ 7 Ultrasound Machine (Philips EPIQ 7 Cardiac Ultrasound; Bothell, WA, USA) and $2.5 \mathrm{MHz}$ probe. Echocardiographic measurements were made with patients lying in the left lateral position. Left ventricular ejection fraction was calculated using the modified Simpson's formula. Measurements of the left and right cardiac chambers were made in accordance with the imaging guidelines recommended by the American and European Heart Associations [13]. Following the measurements of standard 2D right and left cardiac cavities, anterior and posterior wall aortic diameters at systole $(\mathrm{AoS})$ and diastole (AoD) were calculated from a distance of $3 \mathrm{~cm}$ from the aortic valve using parasternal long axis M-mode imaging. AoS was measured when the aortic valve was open, and AoD was measured based on the peak QRS wave on electrocardiography. The measurements were averaged over 5 consecutive heart beats (Fig. 2). Measurements of left ventricular global longitudinal strain were performed offline using QLab 11.0 (Philips, Andover, MA, USA).

The ASI was calculated using the formulas below [14].

Pulse pressure $(\mathrm{mm} \mathrm{Hg})=$

Systolic blood pressure - Diastolic blood pressure

Aortic strain $(\mathrm{AS})(\%)=100 \times \frac{(\mathrm{AoS}-\mathrm{AoD})}{\mathrm{AoD}}$.

Aortic distensibility $(\mathrm{AD})\left[\frac{1}{\left(10^{3} \times \mathrm{mm} \mathrm{Hg}\right)}\right]=2 \times \frac{\left[\frac{(\mathrm{AoS}-\mathrm{AoD})}{\mathrm{AoD}}\right]}{\mathrm{PP}}$.

Aortic stiffness index $(\mathrm{ASI})=\ln \left(\frac{\mathrm{SBP}}{\mathrm{DBP}}\right)\left[\frac{(\mathrm{AoS}-\mathrm{AoD})}{\mathrm{AoD}}\right]$.

Stroke volume $(\mathrm{SV})(\mathrm{mL})=$ Aortic annular cross -

sectional area $\times$ (Doppler velocity - time integral of aortic flow)

Stroke volume index $(\mathrm{SVi})\left(\frac{\mathrm{mL}}{\mathrm{m}^{2}}\right)=\frac{\mathrm{SV}}{\mathrm{BSA}}$.

Statistical Analysis

Statistical data were analyzed using the SPSS 19.0 (SPSS Inc, Chicago, IL, USA) program. The Kolmogorov-Smirnov test was 
Table 1. Demographic and laboratory findings of COVID-19 patients and the control group

\begin{tabular}{|c|c|c|c|}
\hline & COVID-19 $(n=50)$ & Control $(n=50)$ & $p$ value \\
\hline Age, years & $46.52 \pm 14.68$ & $48.86 \pm 15.37$ & 0.910 \\
\hline \multicolumn{4}{|l|}{ Gender } \\
\hline Male & 20 & 24 & \multirow{2}{*}{0.420} \\
\hline Female & 30 & 26 & \\
\hline Smoking, \% & 15 & 13 & 0.824 \\
\hline $\mathrm{BMI}, \mathrm{kg} / \mathrm{m}^{2}$ & $26.80 \pm 1.61$ & $26.24 \pm 1.80$ & 0.105 \\
\hline Heart rate & $78.58 \pm 13.16$ & $82.16 \pm 15.58$ & 0.218 \\
\hline $\mathrm{SBP}, \mathrm{mm} \mathrm{Hg}$ & $113.42 \pm 14.43$ & $109.42 \pm 12.86$ & 0.147 \\
\hline $\mathrm{DBP}, \mathrm{mm} \mathrm{Hg}$ & $70.40 \pm 10.37$ & $73.68 \pm 10.01$ & 0.111 \\
\hline Glucose, mg/dL & $102.28 \pm 15.40$ & $97.56 \pm 20.24$ & 0.377 \\
\hline Creatinine, $\mathrm{mg} / \mathrm{dL}$ & $0.75 \pm 0.13$ & $0.70 \pm 0.27$ & 0.497 \\
\hline Hemoglobin, g/dL & $13.88 \pm 1.15$ & $14.04 \pm 1.15$ & 0.491 \\
\hline $\mathrm{LDL}, \mathrm{mg} / \mathrm{dL}$ & $128.30 \pm 37.40$ & $135.25 \pm 46.31$ & 0.500 \\
\hline $\mathrm{HDL}, \mathrm{mg} / \mathrm{dL}$ & $56.33 \pm 15.26$ & $51.61 \pm 16.56$ & 0.257 \\
\hline Triglyceride, $\mathrm{mg} / \mathrm{dL}$ & $133.90 \pm 65.53$ & $152.44 \pm 72.43$ & 0.285 \\
\hline
\end{tabular}

$\mathrm{BMI}$, body mass index; SBP, systolic blood pressure; $\mathrm{DBP}$, diastolic blood pressure; LDL, low-density lipoprotein; HDL, high-density lipoprotein.
Table 2. Clinical characteristics and laboratory findings of COVID-19 patients

\begin{tabular}{ll}
\hline Signs and symptoms & COVID-19 $(n=50)$ \\
\hline Fever, $n(\%)$ & $37(74)$ \\
Cough, $n(\%)$ & $8(16)$ \\
Myalgia, $n(\%)$ & $8(16)$ \\
Inpatient treatment, $n(\%)$ & $6(12)$ \\
Lung infection, $n$ (\%) & $9(18)$ \\
Laboratory data, median (per 25-75) & $145(55-408)$ \\
$\quad$ Serum ferritin & $45(23-107)$ \\
D-dimer, ng/mL & $21(6.8-45)$ \\
$\quad$ Hs-TnT, ng/L & $7(6-11)$ \\
$\quad$ Hospital stay, days & $5(10)$ \\
Treatment, $n(\%)$ & $3(6)$ \\
$\quad$ HFNC/NIMV & $1(2)$ \\
ICU admission & \\
Invasive mechanical ventilation & \\
\hline
\end{tabular}

Hs-TnT, high-sensitive cardiac troponin $\mathrm{T}$; ICU, intensive care unit; HFNC, high-flow nasal cannula; NIMV, noninvasive mechanic ventilation.

Table 3. Correlation of variables with vascular stiffness in patients with COVID-19

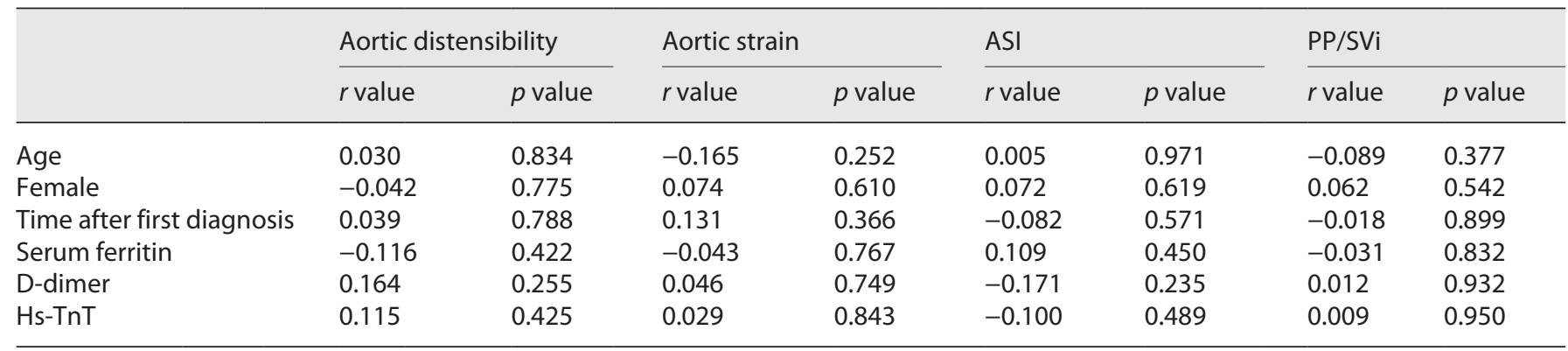

ASI, aortic stiffness index; Hs-TnT, high-sensitive cardiac troponin T; PP/SVi, pulse pressure/stroke volume index.

used to evaluate the distribution of continuous variables. Continuous variables are expressed as mean \pm standard deviation, and categorical variables are expressed as percentages and numbers. Data are presented as median (interquartile range) for continuous variables. The $t$ test and Mann-Whitney U-test were used to compare normally distributed data and non-normally distributed data, respectively. The $\chi^{2}$ test was used to compare the odds ratios of categorical variables. Pearson's test was used for correlation analysis. $p$ values below 0.05 were considered statistically significant. Our study was evaluated with post hoc power analysis using $\mathrm{G}^{*}$ Power (software version 3.1.9.6) (effect size 0.60 , alpha error: 0.05 , and 50 patients in group 1 and 50 patients in group 2), which provided 0.9089529 power for the independent samples $t$ test.

\section{Results}

The study comprised 100 individuals, including COVID- 19 survivors (20 male and 30 female) and the control group (24 male and 26 female). There was no in-hospital mortality in our study. The mean age of the COVID-19 survivors was $46.52 \pm 14.68$ years, whereas the mean age of the control group was $48.86 \pm 15.37$ years. The demographic and laboratory data of the patients are shown in Table 1.

All patients in the hospital required nasal oxygen support. Oxygen support was provided by high-flow nasal cannula or noninvasive mechanic ventilation in 5 patients. Oxygen support was provided by orotracheal intu- 
Table 4. Echocardiographic and aortic elasticity parameters of the study population

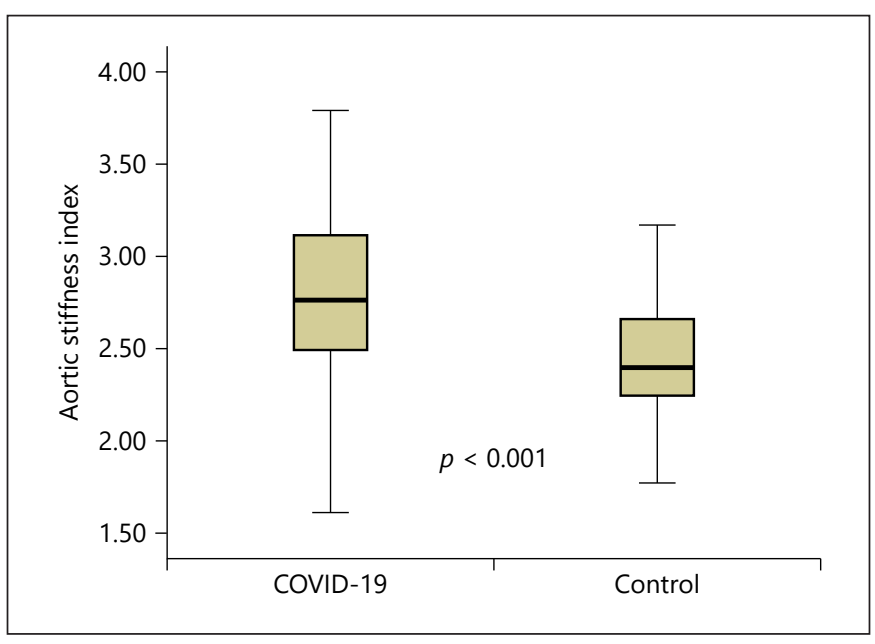

Fig. 3. Comparison of the ASI for COVID-19 survivors and control groups.

\begin{tabular}{lllr}
\hline & COVID-19 $(n=50)$ & Control $(n=50)$ & $p$ value \\
\hline LVEDD, mm & $43.80 \pm 2.36$ & $42.82 \pm 3.47$ & 0.103 \\
LVESD, mm & $28.46 \pm 2.04$ & $27.96 \pm 2.19$ & 0.500 \\
Left ventricle & & & \\
LVEF, \% & $58.02 \pm 4.84$ & $59.78 \pm 4.90$ & 0.075 \\
GLS, \% & $-19.18 \pm 1.00$ & $-22.44 \pm 1.70$ & $<0.001$ \\
SV, mL & $69.28 \pm 11$ & $72.74 \pm 10.21$ & 0.106 \\
SVi, mL/m ${ }^{2}$ & $36.04 \pm 5.99$ & $38.05 \pm 5.50$ & 0.084 \\
IVS thickness, mm & $10.84 \pm 1.25$ & $10.70 \pm 1.16$ & 0.564 \\
PW thickness, mm & $8.56 \pm 1.19$ & $8.46 \pm 1.16$ & 0.673 \\
Mitral E/A ratio & $1.02 \pm 0.13$ & $0.99 \pm 0.15$ & 0.320 \\
LA diameter, mm & $37.18 \pm 2.14$ & $36.38 \pm 3.12$ & 0.139 \\
RA diameter, mm & $30.66 \pm 3.11$ & $31.32 \pm 2.04$ & 0.214 \\
RV diameter, mm & $28.66 \pm 3.30$ & $29.14 \pm 2.93$ & 0.444 \\
TAPSE, mm & $18.76 \pm 2.23$ & $19.32 \pm 2.77$ & 0.560 \\
SPAP, mm Hg & $20.78 \pm 2.35$ & $19.82 \pm 2.49$ & 0.960 \\
Mild MR, $n$ (\%) & $11(22)$ & $6(12)$ & 0.180 \\
Mild AR, $n$ (\%) & $6(12)$ & $4(8)$ & 0.504 \\
Aortic elasticity parameters & & & \\
Aortic systolic diameter, cm & $3.5 \pm 0.2$ & $3.4 \pm 0.2$ & 0.073 \\
Aortic diastolic diameter, cm & $3.1 \pm 0.2$ & $2.9 \pm 0.1$ & $<0.001$ \\
PP & $43.02 \pm 14.05$ & $35.74 \pm 9.86$ & 0.004 \\
Aortic distensibility & $5.61 \pm 3.57$ & $8.31 \pm 3.82$ & $<0.001$ \\
Aortic strain & $10.56 \pm 4.91$ & $13.88 \pm 5.86$ & 0.003 \\
ASI & $2.82 \pm 0.47$ & $2.46 \pm 0.45$ & $<001$ \\
PP/SVi & $1.25 \pm 0.47$ & $0.98 \pm 0.28$ & 0.001 \\
\hline
\end{tabular}

LVEF, left ventricular ejection fraction; GLS, global longitudinal strain; LVEDD, left ventricular end diastolic dimension; LVESD, left ventricular end systolic dimension; IVS, interventricular septum; $\mathrm{PW}$, posterior wall; $\mathrm{E}$, peak transmitral flow velocities at early filling phase; $A$, peak transmitral flow velocities at late filling phase; $L A$, left atrium; $R A$, right atrium; RV, right ventricle; SV, stroke volume; SVi, stroke volume index; TAPSE, tricuspid annular systolic excursion; SPAP, systolic pulmonary artery pressure; MR, mitral regurgitation; AR, aortic regurgitation; PP, pulse pressure; ASI, aortic stiffness index. bation in only 1 patient. Three patients were admitted to the intensive care unit (Table 2). There was no correlation between aortic elasticity, ASI, PP/SVi, and AD with age, female gender, and time since the diagnosis of COVID-19, serum ferritin, D-dimer, and high-sensitivity cardiac troponin (Hs-TnT) (Table 3).

Table 4 shows the echocardiographic and aortic elasticity parameters of patients. Mean left ventricular global longitudinal strain was statistically significantly different between COVID-19 survivors and the control group $(-19.18 \pm 1.00$ and $-22.44 \pm 1.70$, respectively; $p<0.001)$.

The mean ASI was significantly higher in COVID-19 survivors compared to the control group $(2.8 \pm 0.4$ and $2.4 \pm 0.4$, respectively; $p<0.001$ ) (Fig. 3). Mean PP/SVi was significantly higher in COVID-19 survivors compared to the control group $(1.25 \pm 0.47$ and $0.98 \pm 0.28$, respectively; $p=0.001$ ). Similarly, PP was significantly 
higher in COVID-19 survivors compared to the control group (43.02 \pm 14.05 and $35.74 \pm 9.86$, respectively; $p=$ $0.004)$. On the other hand, mean $\mathrm{AD}$ and aortic strain (AS) were significantly lower in COVID-19 survivors compared to the control group (5.6 \pm 3.5 and $8.3 \pm 3.8$, respectively; $p<0.001)$ and $(10.56 \pm 4.91$ and $13.88 \pm 5.86$, respectively; $p=0.003$ ) (Table 4 ).

\section{Discussion}

In this study, it was demonstrated for the first time using echocardiographic imaging that $\mathrm{AS}$ and $\mathrm{AD}$ decreased and PP, ASI, and PP/SVi increased significantly in COVID-19 survivors compared to healthy adult controls. The clinical features of COVID-19 patients can range from asymptomatic to acute respiratory distress and death [16]. Heart rate tends to be higher in survivors of COVID-19, and our study results differ from literature data. The difference in clinical variables such as sympathetic system activation and cytokine storm may have caused this difference [17].

Although COVID-19 disease is associated with pneumonia, it can affect many systemic organs due to endothelial damage. Endothelial damage in COVID-19 patients can be caused by the direct effect of severe acute respiratory syndrome coronavirus 2 (SARS-CoV-2) virus or can be indirectly caused by cytokine and complement activation [18]. In addition, other mechanisms (subintimal bleeding, edema, inflammation, etc.) are believed to be key elements in the pathogenesis of arterial damage [19]. Endothelial damage and subsequent atherosclerotic processes cause thickening and stiffness of the tunica media layer as the prevalence and severity of atherosclerosis increases, leading to arterial stiffness [20]. Şatiroğlu et al. [21] performed coronary angiography for suspected coronary artery disease and found that the increased ASI was proportional to the prevalence of CAD and the number of coronary vessels involved. Since serious adverse cardiovascular outcomes may occur in patients with an increased ASI, it is important to identify these patients with a noninvasive method before the manifestation of cardiovascular diseases.

Rodilla et al. [22] showed that increased arterial stiffness was associated with mortality in hospitalized patients with a diagnosis of COVID-19. The investigators used PP to define arterial stiffness and showed that individuals with values above $60 \mathrm{~mm} \mathrm{Hg}$ are at high risk for mortality [22]. Our study differed in that in addition to PP, echocardiographic imaging and arterial elasticity parameters were compared between the groups. Compared

Aortic Elasticity Parameters and COVID-19 to the mean PP of $74 \mathrm{~mm} \mathrm{Hg}$ in the study by Rodilla et al. [22], mean PP in COVID-19 survivors was $43 \mathrm{~mm} \mathrm{Hg}$ in the present study. Compared to the study by Rodilla et al. [22], the younger age of our patients explains the difference in PP. In long-term follow-up, it will be understood whether PP values have an effect on mortality risk, especially in young patients. Hypertension and diastolic dysfunction are associated with abnormal aortic wall compliance. Early vascular aging is observed in hypertensive patients [23]. Advanced age and hypertension are the most important factors in arterial stiffness, and exclusion of patients with advanced age and hypertension in our study explains the lower value obtained and makes the result more meaningful. Survivors of COVID-19 are likely to be at higher risk than the control group, due to the possibility of adding comorbid conditions in the coming years.

A recent study evaluated endothelial functions of COVID-19 survivors 4 months after infection along with carotid-femoral PWV, central BP, and aortic elastic parameters. The results of the study showed impaired endothelial functions and arterial stiffness [24]. In another study, Schnaubelt et al. [25] measured PWV, which is a measure of arterial stiffness, using an oscillometric pulse wave device in peripheral arteries of patients with COVID-19. They showed that increased PWV was associated with increased in-hospital mortality and prolonged hospitalizations in patients with COVID-19 [25]. The PWV technique is used to evaluate arterial stiffness, and it seems that alternative methods such as echocardiographic imaging may be useful in the evaluation of arterial stiffness. As seen in our study, even after weeks, COVID-19 survivors had higher arterial stiffness index compared to healthy individuals.

SARS-CoV-2 binds to the angiotensin-converting enzyme 2 receptor using the spike protein [26]. The presence of angiotensin-converting enzyme 2 in cardiomyocytes outside of lung tissue makes cardiac tissue a potential target for the virus [27]. The results of our study proved increased aortic diastolic diameters in patients who recovered from COVID-19 compared to the control group. The basis of this change is likely to be decreased elasticity of the ascending aorta. As a matter of fact, endothelial dysfunction may occur either directly through immunological pathways or during infection with SARS-CoV-2 [28, 29]. Therefore, it is possible for patients with COVID-19 to have loss of elasticity of the ascending aorta due to endothelial damage and an increase in the diameter of the ascending aorta in the following period. Loss of elasticity of the ascending aorta is an independent predictor of allcause mortality and cardiovascular events, even in individuals without known cardiovascular disease [30]. 
In line with the results obtained in our study, calculation of the ASI with echocardiographic imaging can be used as an affordable and easy method for the assessment of cardiovascular disease risk in COVID-19 survivors. A limitation of this study is that it has a small sample size due to the excess of exclusion criteria. Second, this study was not a follow-up study. Conducting long-term followup studies using the arterial stiffness index may increase our knowledge about long-term cardiac complications in COVID-19 survivors.

\section{Conclusion}

COVID-19 has negative effects on the cardiovascular system the underlying mechanisms of which are unclear. Adverse changes in the arterial wall are possible in COVID-19 infection. To conclude, this study is the first to demonstrate that $\mathrm{AS}$ and $\mathrm{AD}$ decreased, and $\mathrm{PP}, \mathrm{PP} / \mathrm{SVi}$, and ASI increased in COVID-19 survivors using the echocardiographic imaging method.

\section{Acknowledgments}

This study was supported by Çanakkale Onsekiz Mart University Scientific Research Coordination Unit (Project No. THD2021-3621).

\section{Statement of Ethics}

The study approval was obtained from the Turkish Ministry of Health Coronavirus Scientific Board (reference No. 2020-0928T11_37_53) and Ethics Committee of Clinical Research of
Çanakkale Onsekiz Mart University (Date: February 10, 2021, and Decision No. 2011-KAEK-27/2021-E.2000150501). The study was performed in accordance with the Declaration of Helsinki. Both verbal and written informed consents were obtained from the participants.

\section{Conflict of Interest Statement}

No conflict of interest was declared by the authors.

\section{Funding Sources}

This study was supported by Çanakkale Onsekiz Mart University, the Scientific Research Coordination Unit (Project No. THD2021-3621). The research sponsors did not participate in the study design, data collection, analysis, and interpretation, not involved in the writing of the manuscript, and the decision to submit the manuscript for publication.

\section{Author Contributions}

All the authors made substantial contributions to the conception and/or design of the work and also to the acquisition, analysis, or interpretation of the data as well as drafting and revising the paper.

\section{Data Availability Statement}

Raw data were generated at Çanakkale Onsekiz Mart University, Canakkale, Turkey. The authors confirm that data supporting the findings of this study are available at our university hospital.

\section{References}

1 Wang D, Hu B, Hu C, Zhu F, Liu X, Zhang J, et al. Clinical characteristics of 138 hospitalized patients with 2019 novel coronavirus-infected pneumonia in Wuhan, China. JAMA. 2020;323(11):1061-9.

2 Clerkin KJ, Fried JA, Raikhelkar J, Sayer G, Griffin JM, Masoumi A, et al. COVID-19 and cardiovascular disease. Circulation. 2020; 141(20):1648-55.

3 Jin Y, Ji W, Yang H, Chen S, Zhang W, Duan G. Endothelial activation and dysfunction in COVID-19: from basic mechanisms to potential therapeutic approaches. Signal Transduct Target Ther. 2020;5(1):293.
4 Mulders TA, van den Bogaard B, Bakker A, Trip MD, Stroes ES, van den Born BJ, et al. Arterial stiffness is increased in families with premature coronary artery disease. Heart. 2012;98(6):490-4.

5 Mancia G, Fagard R, Narkiewicz K, Redon J, Zanchetti A, Böhm M, et al. 2013 ESH/ESC guidelines for the management of arterial hypertension: the task force for the management of arterial hypertension of the European Society of Hypertension (ESH) and of the European Society of Cardiology (ESC). Eur Heart J. 2013;34(28):2159-219.

$6 \mathrm{Kim} \mathrm{HL}$, Kim SH. Pulse wave velocity in atherosclerosis. Front Cardiovasc Med. 2019;6: 113.
7 Vlachopoulos C, Aznaouridis K, Stefanadis C. Prediction of cardiovascular events and allcause mortality with arterial stiffness: a systematic review and meta-analysis. J Am Coll Cardiol. 2010;55(13):1318-27.

8 Kollias A, Kyriakoulis KG, Gravvani A, Anagnostopoulos I, Stergiou GS. Automated pulse wave velocity assessment using a professional oscillometric office blood pressure monitor. J Clin Hypertens. 2020;22(10):1817-23.

9 Asmar R, Benetos A, Topouchian J, Laurent P, Pannier B, Brisac AM, et al. Assessment of arterial distensibility by automatic pulse wave velocity measurement. Validation and clinical application studies. Hypertension. 1995; 26(3):485-90. 
10 Cecelja M, Chowienczyk P. Role of arterial stiffness in cardiovascular disease. JRSM Cardiovasc Dis. 2012;1(4):cvd.2012.012016.

11 Palmieri V, Bella JN, Gerdts E, Wachtell K, Papademetriou V, Nieminen MS, et al. Change in pulse pressure/stroke index in response to sustained blood pressure reduction and its impact on left ventricular mass and geometry changes: the life study. Am J Hypertens. 2008;21(6):701-7.

12 TC Ministry of Health. Daily COVID-19 table [internet]. TC Ministry of Health; 2021 [cited 2021 Jun 5]. Available from: https://covid19bilgi.saglik.gov.tr.

13 Lang RM, Bierig M, Devereux RB, Flachskampf FA, Foster E, Pellikka PA, et al. American Society of Echocardiography's Nomenclature and Standards Committee; Task Force on Chamber Quantification; American College of Cardiology Echocardiography Committee; American Heart Association; European Association of Echocardiography, EuropeanSocietyofCardiology.Recommendations for chamber quantification. Eur J Echocardiogr. 2006;7(2):79-108.

14 Pitsavos C, Toutouzas K, Dernellis J, Skoumas J, Skoumbourdis E, Stefanadis C, et al. Aortic stiffness in young patients with heterozygous familial hypercholesterolemia. Am Heart J. 1998;135(4):604-8.

15 Dubin J, Wallerson DC, Cody RJ, Devereux RB. Comparative accuracy of Doppler echocardiographic methods for clinical stroke volume determination. Am Heart J. 1990;120: $116-23$.

16 Sung HK, Kim JY, Heo J, Seo H, Jang YS, Kim $\mathrm{H}$, et al. Korea National Committee for clinical management of COVID-19. Clinical course and outcomes of 3,060 patients with coronavirus disease 2019 in Korea, JanuaryMay 2020. J Korean Med Sci.. 2020;35(30): e280.

17 Wasim D, Alme B, Jordal S, Lind Eagan TM, Tadic M, Mancia G, et al. Characteristics of 24-hour ambulatory blood pressure monitoring in a COVID-19 survivor. Future Cardiol. 2021;17(8):1321-6.

18 Rochette L, Zeller M, Cottin Y, Vergely C. GDF15: an emerging modulator of immunity and a strategy in COVID-19 in association with iron metabolism. Trends Endocrinol Metab. 2021;32(11):875-89.

19 Saeed S, Mancia G. Arterial stiffness and COVID-19: a bidirectional cause-effect relationship. J Clin Hypertens. 2021;23(6):1099-103.

20 Ekholm M, Kahan T. The impact of the reninangiotensin-aldosterone system on inflammation, coagulation, and atherothrombotic complications, and to aggravated COVID-19. Front Pharmacol. 2021;12:640185.

21 Şatiroğlu Ö, Bostan M, Bayar N, Cicçek Y, Cetin M, Bozkurt E. Relation between aortic stiffness and extension of coronary artery disease. Turk J Med Sci. 2012;42(3):417-24.

22 Rodilla E, López-Carmona MD, Cortes X, Cobos-Palacios L, Canales S, Sáez MC, et al. SEMI-COVID-19 network. Impact of arterial stiffness on all-cause mortality in patients hospitalized with COVID-19 in Spain. Hypertension. 2021;77(3):856-67.

23 Mancia G, De Backer G, Dominiczak A, Cifkova R, Fagard R, Germano G, et al. 2007 guidelines for the management of arterial hypertension: the task force for the management of arterial hypertension of the European Society of Hypertension (ESH) and of the Euro- pean Society of Cardiology (ESC). Eur Heart J. 2007;28(12):1462-536.

24 Lambadiari V, Mitrakou A, Kountouri A, Thymis J, Katogiannis K, Korakas E, et al. Association of COVID-19 with impaired endothelial glycocalyx, vascular function and myocardial deformation 4 months after infection. Eur J Heart Fail. 2021;23(11):1916-26.

25 Schnaubelt S, Oppenauer J, Tihanyi D, Mueller M, Maldonado-Gonzalez E, Zejnilovic S, et al. Arterial stiffness in acute COVID-19 and potential associations with clinical outcome. J Intern Med. 2021;290(2):437-43.

26 Nicin L, Abplanalp WT, Mellentin H, Kattih B, Tombor L, John D, et al. Cell type-specific expression of the putative SARS-CoV-2 receptor ACE2 in human hearts. Eur Heart J. 2020;41(19):1804-6.

27 Chen L, Li X, Chen M, Feng Y, Xiong C. The ACE2 expression in human heart indicates new potential mechanism of heart injury among patients infected with SARS-CoV-2. Cardiovasc Res. 2020;116(6):1097-100.

28 Szekely Y, Lichter Y, Taieb P, Banai A, Hochstadt A, Merdler I, et al. Spectrum ofcardiac manifestations in COVID-19: a systematic echocardiographic study. Circulation. 2020; 142(4):342-53.

29 Schott JP, Mertens AN, Bloomingdale R O'Connell TF, Gallagher MJ, Dixon S, et al. Transthoracic echocardiographic findings in patients admitted with SARS-CoV-2 infection. Echocardiography. 2020;37(10):1551-6.

30 Redheuil A, Wu CO, Kachenoura N, Ohyama Y, Yan RT, Bertoni AG, et al. Proximal aortic distensibility is an independent predictor of all-cause mortality and incident CV events: the MESA study. J Am Coll Cardiol. 2014;64:2619-29. 